\title{
Erratum to: Genomics-Guided Precise Anti-Epileptic Drug Development
}

\author{
Norman Delanty ${ }^{1,2} \cdot$ Gianpiero Cavalleri $^{2}$
}

Published online: 21 September 2017

(C) Springer Science+Business Media, LLC 2017

\section{Erratum to: Neurochem Res (2017) 42:2084-2088 \\ DOI 10.1007/s11064-017-2312-y}

The original version of this article unfortunately contained a mistake. The family name of the second author has been misspelled as Cavallleri instead of Cavalleri. The last name is corrected as with this erratum.

The online version of the original article can be found under doi:10.1007/s11064-017-2312-y.

Norman Delanty

normandelanty@beaumont.ie

1 Department of Neurology, Beaumont Hospital, Royal College of Surgeons in Ireland, Dublin, Ireland

2 Department of Molecular and Cellular Therapeutics, Royal College of Surgeons in Ireland, Dublin, Ireland 